\title{
Violencia contra migrantes: escenario común tras la guerra contra el crimen organizado en México* / Violence
}

\author{
against migrants: a common scenario in the \\ war against organized crime in Mexico
}

\section{Paola lliana de la Rosa Rodríguez ${ }^{* *}$}

\section{RESUMEN}

La migración se ha suscitado desde la antigüedad, sin embargo, que la delincuencia organizada intercepte y obstruya este tránsito resulta un fenómeno de mayor contundencia en la actualidad. Este artículo estudia específicamente la migración centroamericana en tránsito por México, para explicar que "la guerra contra las drogas" fue un factor preponderante en el aumento de la violencia y las transgresiones contra estos migrantes. Bajo esta premisa, el artículo explica que la intensificación del combate contra grupos narcotraficantes generó una violencia generalizada, sin precedentes. A través del análisis documental, en su segunda parte, discute los impactos de la narco-guerra en los derechos humanos de los migrantes. La tercera parte emplea el análisis comparativo cualitativo (oca) para determinar las variables presentes en la criminalidad contra esta población y comprobar las causales de este fenómeno. Se concluye que los migrantes indocumentados en tránsito por México son víctimas colaterales de una lucha contra la delincuencia organizada.

PALABRAS CLAVE: Migración, crimen organizado, criminalidad contra inmigrantes, secuestro de migrantes, violencia generalizada.

\begin{abstract}
While migration has been occurring since ancient times, the involvement of organized crime in intercepting and obstructing this movement of people has become a much more pronounced phenomenon in recent years. The present article specifically focuses on Central American migration in transit through Mexico to explain that "the war on drugs" was a key factor in the increased violence and crime perpetuated against migrants. Under this premise, the article explains that the intensification of the battle against drug trafficking groups generated an unprecedented level of generalized violence. The second section uses documentary analysis to discuss the impact of the war on drugs on the human rights of migrants.

Qualitative comparative analysis (oca) is used in the third section to determine the variables present in the criminality manifested against this population and identify its causes. The present paper concludes that undocumented migrants in transit through Mexico are collateral victims of the fight against organized crime.
\end{abstract}

KEY WORDS: Migration, organized crime, criminality against immigrants, kidnapping of migrants, generalized violence.

\footnotetext{
* Artículo de investigación. Recibido el 22 de enero de 2020 y aceptado para su publicación el 29 de julio de 2020.

** Profesora investigadora en la Universidad Autónoma de San Luis Potosí, México. / paola.delarosa@uaslp.mx / orcid.org/0000-0001-6620-3589
} 


\section{SUMARIO}

1. Introducción

2. Lucha contra grupos criminales narcotraficantes y violencia generalizada

3. Desaparición y secuestro de migrantes

4. ¿Qué determina el método ocA sobre este fenómeno?

5. Conclusiones

\section{Introducción}

En forma simultánea, cantidades copiosas de drogas ingresan a México desde las fronteras norte y sur del país, mientras miles de centroamericanos indocumentados cruzan el territorio de la nación hacia Estados Unidos. Los datos más actuales que proporciona el boletín mensual de estadísticas migratorias 2020 puntualizan que la cantidad de eventos de extranjeros presentados ante las oficinas de migración de enero a abril de 2020 fue de 3131 salvadoreños, 11106 guatemaltecos y 14854 hondureños. ${ }^{1}$ Estos tres países son conocidos como el Triángulo del Norte.

La migración siempre ha constituido un elemento de la condición humana. ${ }^{2}$ Si bien los flujos de personas en movilidad humana han aumentado a nivel global, ${ }^{3}$ las dinámicas en que se presentan son diversas y complejas, y no se pueden hacer generalizaciones estrictas. Bajo esa premisa, para entender la migración, hay que estudiar las circunstancias en que esta se presenta. ${ }^{4}$

El movimiento migratorio objeto de este estudio se enfoca en la ahora denominada migración irregular centroamericana que transita por México y se dirige a Estados Unidos. Del año 2007 al 2010, 1.9 millones de extranjeros entraron por la frontera sur de México, de los cuales 17\% correspondieron a migrantes indocumentados, de acuerdo con la cantidad de personas que se registran en las estaciones migratorias. ${ }^{5}$ El Instituto Nacional de Migración

1 "Extranjeros presentados y devueltos, 2020", Boletín mensual de estadisticas migratorias. Disponible en: http:// portales.segob.gob.mx/es/PoliticaMigratoria/CuadrosBOLETIN?Anual=2020\&Secc=3

2 BADE, KLAUS, "Migration History", International Encyclopedia of the Social \& Behavioral Sciences, 2015, pp. 446-451.

3 González, Gonzalo Carrasco, "La migración centroamericana en su tránsito por México hacia los Estados Unidos", Alegatos, vol. 27, núm. 83, pp. 169-194.

4 Abubakar, Ibrahim; Aldridge, Robert; Devakumar, Delan; Orcutt, Miriam; Burns, Rachel y Barreto, Mauricio, "The UCl-Lancet Commission on Migration and Health: the health of a world on the move", The Lancet, vol. 392, núm. 10164, pp. 2606-2654.

${ }^{5}$ Rodriguez Chàvez, Ernesto; Berumen, Salvador y Ramos, Luis Felpe, "Migración centroamericana de tránsito irregular por México. Estimaciones y características generales", Apuntes sobre Migración, México, Centro de Estudios Migratorios del Instituto Nacional de Migración, 2011, p.1. 
(INM) refirió que, del año 2005 al 2010, de 92 a 95\% de los migrantes alojados en las estaciones migratorias eran nacionales de Guatemala, Honduras, El Salvador y Nicaragua. De los migrantes centroamericanos, $45.5 \%$ proceden de Guatemala, seguidos por los hondureños (32.6\%). Todos ellos dejan sus lugares de origen debido a las crisis económicas y sociales, así como a la nula capacidad de estas naciones de procurar condiciones de vida digna para sus ciudadanos. Así, sus movimientos constituyen una estrategia para lidiar con estas situaciones y superarlas. ${ }^{6}$

En su trayecto, los centroamericanos son expuestos a abusos y crímenes que ponen fin a su propósito. Algunas estimaciones de dichas transgresiones han sido reportadas por la Comisión Nacional de Derechos Humanos. La institución refiere que, en el año 2009, cerca de diez mil personas, en su mayoría migrantes de Centroamérica, habían sido víctimas de secuestro en un periodo de seis meses. Un año después, esa cifra se incrementó a alrededor de once mil y se presentaron 214 casos de secuestro masivo de migrantes, en un periodo de seis meses. Por su parte, el Instituto Nacional de Migración en México (INM) documentó que, del año 2012 al 2017, se reportaron 2912 casos de migrantes víctimas de algún delito. ${ }^{7}$

Dicha panorámica ha sido la razón de que los mismos migrantes expresen que "la peor parte del viaje no fuera cruzar la frontera México-Estados Unidos, sino atravesar México”. El planteamiento de este trabajo invoca que la criminalidad contra los extranjeros indocumentados en México paradójicamente ha ido incrementando con el combate al crimen organizado. El periodo al que se hará referencia en esta investigación comienza en el 2006, año en que la presidencia en México declaró la guerra contra el narcotráfico, y concluye al inicio del mandato peñista.

El objetivo general es explicar que las acciones y políticas de la guerra contra el tráfico de drogas y, por ende, contra la delincuencia organizada, fueron un factor primordial en el aumento de la violencia a los transmigrantes centroamericanos. Es por ello que, entre las preguntas que guían esta investigación, se encuentran las siguientes: ¿de qué forma el combate al narcotráfico y su escalada de violencia ha afectado los derechos humanos de los migrantes indocumentados?, ¿por qué los cárteles de la droga son predadores de los extranjeros indocumentados?, ¿cuáles son los factores que inciden en la violencia contra migrantes centroamericanos en México?

\footnotetext{
${ }^{6}$ Laczko, Frank y Aghazarm, Christine, Migration, Environment and Climate Change: assessing the evidence, Suiza, International Organization for Migration, 2009.

7 Higareda, Diana y Peralta, Montserrat, "Secuestros azotan a migrantes de Centroamérica", El Universal, 12 de agosto, 2018. Disponible https://www.eluniversal.com.mx/nacion/sociedad/secuestros-azotan-migrantes-de-centroamerica
} 
En este escenario, se aprecia como variable dependiente la criminalidad ejercida en México contra los extranjeros indocumentados, provenientes del Triángulo del Norte. Como variables independientes, se consideran el control de los cárteles en cada estado, la violencia generada en los estados, las rutas migrantes, así como la alineación de los partidos en el poder de los gobiernos estatales con el poder federal durante este periodo.

La metodología empleada consistió en la recolección de datos obtenidos de organizaciones que brindan apoyo a migrantes, tales como las Casas del Migrante, la Oficina en Washington para Asuntos Latinoamericanos (WOLA) y Fundar, el Centro de Análisis e Investigación, entre otras. Asimismo, se recabaron y analizaron estadísticas de delitos y violaciones a los derechos humanos contra personas migrantes y se buscó información en los registros del Inegi, procuradurías de atención a migrantes e informes de la Comisión Nacional de Derechos Humanos.

Aunado a lo anterior, se utilizó la técnica analítica qualitative comparative analisis (QCA) - metodología que sistematiza información y que emplea el álgebra booleana para codificar variables, compararlas y encontrar los casos técnicamente posibles de un fenómeno social-, a manera de deducir los elementos que están presentes en los estados con mayores índices de criminalidad en contra de la población migratoria. Este método se utiliza para analizar casos multicausales, es decir, se emplea para estudiar los varios aspectos que inciden en la explicación de un fenómeno. Así, permite encontrar cuáles son las variables que están presentes y son la génesis de una manifestación social. ${ }^{8}$

A mayor abundamiento, se eligió el método (QCA) porque este provee comparaciones lógicas que se emplean para interpretar y explicar cómo se integran las diferentes variables de un acontecimiento, utilizando la lógica y el análisis cuantitativo. A través de la base en que se presentan, tanto la variable dependiente como las independientes (que previamente fueron definidas y estudiadas por la suscrita investigadora), el método genera una tabla de verdad. En ella, se reproduce una reducción lógica de información con las combinaciones de variables posibles y presentes de un fenómeno. Esta metodología elimina las variables con poca ganancia informativa, proyectando como resultado solo aquellas que tienen mayor potencial para explicar el fenómeno estudiado. ${ }^{9}$

\footnotetext{
${ }^{8}$ Ragin, Charles, Qualitative Comparative Analysis using Fuzzy Sets (fSQCA). Configurational comparative methods: Qualitative comparative analysis (QCA) and related techniques, 2009, vol. 51, p. 87-121.

9 Solis Delgadillo, Juan Mario; Cerna Villagra, Sarah Patricia y Peris Castigloni, Carlos Anibal, "¿Qué explica la violencia legal en Paraguay? Un estudio con intención comparativa", Perfiles latinoamericanos, vol. 27, núm. 53, pp. 7 y 18.
} 


\section{Lucha contra grupos criminales narcotraficantes y violencia generalizada}

Valga mencionar que, a lo largo de las siete décadas que la presidencia de México estuvo gobernada por el PRI, los cárteles del narcotráfico estuvieron vinculados al poder político encabezado por el partido hegemónico. Una vez que el PAN ganó la banca presidencial, se dio una transformación, pues la relación del gobierno y el narcotráfico se fracturó. Uno de sus efectos fue la batalla que encabezó Felipe Calderón Hinojosa, ${ }^{10}$ estéril en su propósito, pero que consumió miles de millones de dólares. Además, llamó a la milicia a luchar contra los cárteles de la droga, llevando a cabo operativos policiacos y militares en todo el país, para hacer frente al narcotráfico. Pero el año 2006 estuvo marcado por las más de 2500 personas que murieron en hechos vinculados al tráfico de drogas. Así, los primeros diez meses de la administración calderonista tuvieron un saldo de 2113 asesinatos relacionados con dicha guerra. ${ }^{11}$

Bajo esta misma administración, con el "Operativo Conjunto Michoacán", se desplegaron cerca de seis mil efectivos armados y policías en el estado de Michoacán, para bloquear carreteras y puestos de control policial. ${ }^{12}$ Esto con el fin de ocupar áreas clave, donde se comercializa la droga, y ejecutar cacheos y órdenes de detención contra personas vinculadas al tráfico de drogas. Este fue el primero de varios operativos dominados por las fuerzas militares, lanzados por el nuevo gobierno en los estados mexicanos donde se cree que se concentra el crimen organizado. Asimismo, para coadyuvar a ejecutar la guerra contra las drogas, Felipe Calderón firmó la primera carta de acuerdo sobre la Iniciativa Mérida en el año 2008.

En este mismo tenor, en 2008, México instrumentó otra ofensiva contra el narcotráfico y los secuestros, firmando un pacto para combatir al crimen organizado. ${ }^{13}$ Además, conforme al Acuerdo Nacional publicado el 25 de agosto del 2008, se establece la seguridad pública como una política de Estado. Este acuerdo tuvo entre sus objetivos establecer un sistema nacional de desarrollo policial y apoyar a las entidades federativas en el combate a los delitos más sensibles para la sociedad. También consideró actualizar las licencias colectivas

\footnotetext{
${ }^{10}$ Con Fox, la violencia generada por los cárteles del narcotráfico se había convertido en el principal problema de seguridad en el pais.

${ }^{11}$ Meyer, Maureen, En la encrucijada. Tráfico de drogas, violencia y el Estado mexicano, Washington, Washington Office on Latin America-The Beckley Foundation Drug Policy Programme, 2007.

${ }^{12}$ PréVIIDE, SANTIAgo, "Los roles de las fuerzas armadas en seguridad interior: un estudio comparado en la América Latina del Siglo xxI (2006-2016)", 2017.

${ }^{13}$ Ávila, Antonio, "México lanza una ofensiva inédita contra el narcotráfico y los secuestros. Los tres poderes del Estado firman un pacto para combatir al crimen organizado", El País, 22 de agosto, 2008.
} 
de portación de armas expedidas por la Secretaría de Defensa Nacional para los cuerpos de seguridad pública y consolidar el sistema de información criminal. Esto último con el fin de garantizar el intercambio de información entre instancias y órdenes de gobierno, para combatir el delito, así como ampliar el uso de tecnología para el intercambio de información en el combate a la delincuencia, entre otros aspectos. ${ }^{14}$

Bajo esta misma administración, se acordó con los Estados Unidos el establecimiento de la fuerza de respuesta de la frontera norte, en 2012, con la cual la policía mexicana y agentes antinarcóticos de la DEA interceptarían y arrestarian a narcotraficantes, con el objetivo de desarticularlos. ${ }^{15}$

Si bien entre 2007 y 2011 se capturó a importantes traficantes y se incrementó el decomiso de marihuana, cocaína y metanfetaminas, los esfuerzos en los que miles de efectivos armados combatieron a los cárteles fueron inútiles para abatir la venta de sustancias psicotrópicas. Lo que sí generaron fueron costos considerables. A manera de ilustración, bajo la presidencia de Felipe Calderón, México gastó 46.6 mil millones de dólares en la lucha contra las drogas ${ }^{16} \mathrm{y}$, aunque no existen cifras exactas, el número de muertes debido a esta guerra asciende a más de setenta mil. ${ }^{17}$ Algunas fuentes afirman que la guerra contra el narcotráfico en el sexenio de Calderón costó 120000 vidas. ${ }^{18}$

Además, de acuerdo con Pereyra, ${ }^{19}$ en lo que incidió claramente este enfrentamiento entre el gobierno y los grupos de la droga, fue el desarrollo de una lucha armada entre cárteles. La estrategia de Calderón respecto a la lucha contra los cárteles del narcotráfico fue la militarización ${ }^{20} \mathrm{y}$, con ella, provocar su desmantelamiento, a pesar de los consiguientes índices de violencia sin precedentes. Ilustrando esta situación, los registros del Instituto Nacional de Estadística y Geografía (Inegi) reportaron un aumento bastante significativo

${ }^{14}$ Secretaria de Gobernación, "Acuerdo Nacional por la Seguridad, la Justicia y la Legalidad", Diario Oficial de la Federación, 25 de agosto, 2008. Disponible en: http://www.dof.gob.mx/nota_detalle.php?codigo=5057719\& fecha $=25 / 08 / 2008$

$214{ }^{15}$ Barreda Vidal, Perla Zoraida, "La cooperación bilateral México-Estados Unidos contra la delincuencia organizada trasnacional en el marco de la Iniciativa Mérida", Revista IUS, vol. 8, núm. 34, pp. 42-60.

${ }^{16}$ Seelke, Clare Ribando y Finklea, Kristin, US-Mexican security cooperation: The Mérida initiative and beyond, Washington, Congressional Research Service, 2011, p. 44.

${ }^{17}$ Rosen, Jonathan Daniel y Zepeda Martinez, Roberto, "La guerra contra el narcotráfico en México: una guerra perdida", Reflexiones, vol. 94, núm. 1, p. 162.

${ }^{18}$ Rosen, Jonathan Daniel y Zepeda Martinez, Roberto, "La guerra contra el narcotráfico en México: una guerra perdida", Reflexiones, vol. 94, núm. 1, p. 162.

${ }^{19}$ Pereyra, Guillermo, "México: violencia criminal y guerra contra el narcotráfico", Revista Mexicana de Sociología, vol. 74, núm. 3.

${ }^{20}$ Pereyra, Guillermo, "México: violencia criminal y guerra contra el narcotráfico", Revista Mexicana de Sociología, vol. 74, núm. 3. 
en el número de homicidios en los años 2007 y 2008, pues incrementaron de 8507 a 14 006, y en el año 2009 ascendieron hasta 19803.

Por su parte, Amnistía Internacional informó que entre enero de 2008 y julio de 2009 se cometieron 14000 asesinatos, ${ }^{21}$ estimando que la cifra llegó a 11800 en $2010 .^{22}$ La tasa nacional de homicidios pasó de registrar de 8 a 18 asesinatos por cada 100000 habitantes, entre 2008 y 2009. ${ }^{23}$ Los homicidios llegaron a 27213 en 2011, y solo en el año 2012 ocurrieron 9744. En el periodo de diciembre de 2012 a noviembre de 2013 se registraron 18458 homicidios dolosos. Es decir, un promedio de 1538 homicidios por mes y 50 por día, según el Sistema Nacional de Seguridad Pública. Como se hará referencia, el incremento en la tasa de homicidios está relacionado con esta escalada de violencia, a partir del combate al narcotráfico.

Paradójicamente, durante la administración calderonista, las organizaciones criminales aumentaron, en lugar de disminuir. De seis cárteles de la droga en 2006, se pasó a nueve en $2010,{ }^{24}$ y dieciséis cárteles reconocidos en $2012,{ }^{25}$ sin contabilizar los grupos que ostentan los mismos objetivos. Así pues, las organizaciones criminales se fragmentaron; diversificando sus actividades ilegales, ${ }^{26}$ los grupos que se consolidaron lucharon por poder. De este modo, se constituyeron como rivales de las demás, mientras obtenían ganancias y expandían sus territorios mediante un intensivo uso de la violencia. ${ }^{27}$

En esta guerra, los cárteles de Sinaloa y del Golfo consiguieron un mayor control de las fronteras, manejaron el tráfico a gran escala hacia Estados Unidos e invirtieron grandes sumas de dinero en personal, equipamiento y armas. $^{28}$

En su afán por expandir sus negocios, los cárteles del narcotráfico buscan nuevas rutas en las cuales puedan establecer su poder. Este desplazamiento de redes criminales de una ciudad, estado o región a otra cercana o de un país a

\footnotetext{
${ }^{21}$ Amnesty International, New Reports of Human Rights Violations by the Military, Londres, Amnesty International Publications, 2009.

${ }^{22}$ Guerrero, Eduardo, "Pandillas y cárteles: La gran alianza", Nexos, 1 de junio, 2010. Disponible en: https://www.nexos. com.mx/?p=13690

${ }^{23}$ Escalante Gonzalbo, Fernando, "Homicidios 2008-2009. La muerte tiene permiso", Nexos, 1 de enero, 2011. Disponible en: https://www.nexos.com.mx/?p=14089

${ }^{24}$ Barkeda Vidal, Perla Zoraida, "La cooperación bilateral México-Estados Unidos contra la delincuencia organizada trasnacional en el marco de la Iniciativa Mérida", Revista IUS, vol. 8, núm. 34, p. 58.

${ }^{25}$ Rosen, Jonathan Daniel y Zepeda Martinez, Roberto, "La guerra contra el narcotráfico en México: una guerra perdida", Reflexiones, vol. 94, núm. 1, p. 161.

${ }^{26}$ Guerrero, Eduardo, "Pandillas y cárteles: La gran alianza", Nexos, 1 de junio, 2010. Disponible en: https://www.nexos. com.mx $/ ? p=13690$

${ }^{27}$ Pereyra, Guillermo, "México: violencia criminal y guerra contra el narcotráfico", Revista Mexicana de Sociología, vol. 74 , núm. 3, p. 430.

${ }^{28}$ Ravelo, RicaRdo, "El reparto del mercado", Revista Proceso, núm. 28, pp. 44-47.
} 
otro, en busca de lugares más seguros y autoridades más débiles es denominado "efecto cucaracha". ${ }^{29}$

Para subsistir esta guerra y no ser abatidos, los otros grupos criminales que operaban en el centro, sur, este y oeste del país, fortalecieron negocios ilícitos menos redituables que el tráfico de drogas a gran escala, y más riesgosos y violentos, como el secuestro, la extorsión, la trata, el tráfico de personas y el robo de vehículos y de bancos. Es decir, los intentos por desarticular a las bandas delictivas agravaron los niveles de violencia con la consecuente violación a derechos humanos. ${ }^{30}$ Así, en esta lucha, la violencia se convirtió en el principal recurso para conquistar territorios y defenderlos.

Siguiendo a Pereyra, la violencia es "un medio de sobrevivencia de nuevos grupos criminales y un instrumento para echar a andar la escalada de venganzas, es un recurso de diversificación de negocios ilícitos que aumenta la fragmentación social y la inseguridad".

Con Felipe Calderón, el negocio de la violencia se consolidó ${ }^{31} \mathrm{y}$, debido a que el número de organizaciones crece, las posibilidades de que el gobierno intervenga efectivamente contra una diversidad de grupos son menores. ${ }^{32}$ Ahora bien, ¿cómo se relaciona esta espiral de la violencia -generada a partir de la agenda contra el crimen organizado-, con los migrantes indocumentados en tránsito por México?

Como se ha mencionado, al tratar de sobrevivir la guerra, los narcotraficantes se convirtieron en empresarios de negocios ilícitos con nuevas actividades delictivas, como la piratería, la trata de personas, el secuestro, el robo con violencia y la extorsión, ${ }^{33}$ teniendo como estandarte la brutalidad e intimidación sobre su población objetivo.

De este modo, son frecuentes los robos a indocumentados donde participan los "coyotes" con la delincuencia organizada. De acuerdo con un estudio en el que se entrevistó a 71 migrantes, la quinta parte fueron asaltados en su

\footnotetext{
${ }^{29}$ Bagley, Bruce, ¿Por qué se está perdiendo la guerra contra la droga? (II): de cucarachas, Estados incapaces y legalizaciones nebulosas, 2011.

${ }^{30}$ Sánchez Espinoza, Francisco y Juárez Jaime, Claudia, "Política de seguridad en México: combate al narcotráfico. Entre la seguridad nacional y la seguridad pública", Revista IUS, vol. 13, núm. 44.

${ }^{31}$ En este contexto, la violencia no es solo un instrumento defensivo o disuasivo, sino que tiene como objetivo producir más violencia, al aumentar los negocios violentos adyacentes al narcotráfico y sumar a sus filas a personas vulnerables, tales como los migrantes. Así, los actos violentos de un grupo criminal son imitados por los demás y la violencia llega a crecer a niveles extremos.

${ }^{32}$ Pereyra, Guillermo, "México: violencia criminal y guerra contra el narcotráfico", Revista Mexicana de Sociología, vol. 74, núm. 3, p. 445.

${ }^{33}$ Sánchez Espinoza, Francisco y Juárez Jaime, Claudia, "Política de seguridad en México: combate al narcotráfico. Entre la seguridad nacional y la seguridad pública", Revista IUS, vol. 13, núm. 44, p. 240.
} 
trayecto. ${ }^{34}$ Asimismo, la Casa del Migrante de Saltillo indica que los grupos delictivos han penetrado las rutas clandestinas y, con uso de violencia, se aprovechan de la condición de absoluta vulnerabilidad del migrante: los reclutan, torturan, explotan, abusan sexualmente de ellos a través de la trata, o bien los extorsionan y hacen desaparecer. ${ }^{35}$

Enfrentando la guerra en su contra y aprovechándose de esta situación, los cárteles de Sinaloa, del Golfo y los Zetas comenzaron a proyectar una alta movilidad internacional, reclutando nuevos sicarios y capacitándolos en técnicas paramilitares. Diversificaron los productos traficados, accedieron a armas y nuevas fuentes de financiamiento y, desde entonces, poseen aparatos de inteligencia más poderosos que los de la policía. Como parte de su estrategia, contrataron pandillas y jóvenes marginales para hacer frente a las numerosas bajas.

El caso de las mujeres migrantes es crítico, pues se les asocia con la prostitución y son obligadas a trabajar en ello. Otras son secuestradas y sometidas a la trata y a la explotación. Se les obliga a trabajar en bares, en cantinas, a ejercer la prostitución forzada, la pornografía y el turismo sexual. Además, se les forza a cocinar y limpiar en las "casas de seguridad". En general, se han documentado muchos otros casos de extorsión, engaño, agresión y violación sistemática en el caso de mujeres migrantes. ${ }^{36}$ Pero, a pesar de conocer las atrocidades que las mujeres migrantes han enfrentado, como la violencia sexual y los feminicidios, ellas deciden emprender su camino hacia el norte. ${ }^{37}$

Las narraciones de las víctimas indican que la delincuencia organizada tiene preferencia por la población migrante, pues supone que han pertenecido al ejército, a la guerrilla, o a las pandillas en Centroamérica. Los grupos delincuenciales también convencen a adolescentes, personas discapacitadas y ancianos, quienes son vulnerables entre los ya vulnerables y que, en su desesperación por la supervivencia, aceptan realizar actividades ilícitas. De este modo, el tránsito del migrante se convierte en una oportunidad para que los delincuentes organizados los secuestren o exploten. Contrario a la postura de que los migrantes son delincuentes, las personas en movilidad humana sufren

\footnotetext{
${ }^{34}$ Slack, JeRemy y WhiteFord, Scom, "Viajes violentos: la transformación de la migración clandestina hacia Sonora y Arizona", Norteamérica, vol. 5, núm. 2.

${ }^{35}$ Véase Cuaderno sobre secuestro de migrantes. Dimensión, contexto y testimonios de la experencia de la migración en tránsito por México, México, Centro de Derechos Humanos Miguel Agustín Pro Juárez-Casa del Migrante Saltillo, 2011, p. 62.

${ }^{36}$ CASTILLAS, Rodolfo, "Las rutas de los centroamericanos por México, un ejercicio de caracterización, actores principales y complejidades", Migración y Desarrollo, núm. 10, pp. 157-174.

${ }^{37}$ Morales Hernández, Sandra, "Central American migrants in transit through Mexico women and gender violence; challenges for the Mexican state", Procedia-Social and Behavioral Sciences, vol. 161, p. 263-268.
} 
la migración, les duele la explotación, la trata y la violencia que viven durante el tránsito y los países de destino. ${ }^{38}$

¿Cómo es que, en su búsqueda por tener permanencia en los negocios ilícitos, un objetivo de los grupos criminales que operan en México son los migrantes indocumentados en tránsito por el país? Para sobrevivir en esta agenda belicosa, los grupos delincuenciales tienen que conseguir más adeptos que trabajen o sean obligados a trabajar para la criminalidad. Por ello, los cárteles se convierten en predadores de grupos vulnerables, como los migrantes indocumentados, pues carecen de identidad, en términos formales.

Por otra parte, los delincuentes secuestran a extranjeros, con el fin de obtener información sobre sus familiares en Estados Unidos y obtener rescate por ellos. La mera portación de un celular convierte a los migrantes en un blanco, pues los criminales creen que están en comunicación con familiares que pueden responder económicamente por ellos. En efecto, los zetas así han procedido en años recientes. ${ }^{39}$ Además, los cárteles han adquirido el control de las rutas ferroviarias que utilizan los migrantes para interceptarlos y llevarlos a casas de seguridad, en donde se les forza a llamar a sus familias para pedir el rescate.

En este escenario, las personas que migran son percibidas como objetos de venta y explotación, cuyo valor, incluso, puede incrementar o bajar. ${ }^{40}$ Además de que maltratan, estafan o despojan a migrantes desesperados, los grupos delictivos "los contratan", obligándolos a trabajar con ellos. Las organizaciones criminales han sabido lucrar a cambio de mantener la secrecía del viaje de los migrantes, obteniendo sumas importantes de dinero. Para dejar pasar a los migrantes por las rutas clandestinas, llegan a cobrar a las redes de contrabando hasta tres mil dólares por persona. De hecho, los ingresos de las redes de contrabando han mermado por los cobros que obtiene la delincuencia organizada en este rubro. ${ }^{41}$

Dicho sea de paso, esta clandestinidad de las personas en movilidad ha sido el resultado de la producción de la "ilegalidad" migrante surgida en Estados Unidos. Por tanto, es ocasionada por las severas restricciones que, sobre todo 218 a partir de 1965, incrementaron el número de deportaciones y que quince años después redujeron las cuotas de los ingresos de población migrante. Las leyes

\footnotetext{
${ }^{38}$ Vogt, Wendy A., "Crossing Mexico: Structural violence and the commodification of undocumented Central American migrants", American Ethnologist, vol. 40, núm. 4, pp. 765.

${ }^{39}$ Barros, Gullerrmo, Refugiados centroamericanos: ¿Protegidos o puestos en riesgo por las tecnologías de la comunicación?, 2017.

${ }^{40}$ Vogt, Wendy A., "Crossing Mexico: Structural violence and the commodification of undocumented Central American migrants", American Ethnologist, vol. 40, núm. 4, pp. 764-780.

${ }^{41}$ Izcara Palacios, Simón Pedro, "La contracción de las redes de contrabando de migrantes en México", Revista de Estudios Sociales, núm. 48, pp. 84-99.
} 
de inmigración de 1990 y de 1996 incrementaron los niveles de "ilegalidad", al imponer penas a los indocumentados. ${ }^{42}$

En consecuencia, la necesidad de los migrantes de no ser descubiertos los convierte en una fuente de ingresos para la delincuencia organizada. Esto quiere decir que la implementación de leyes y políticas de control fronterizo más estrictas aumentaron la demanda de contrabandistas y de traficantes de migrantes. Con ello, el contrabando de personas a Estados Unidos se convirtió en un negocio multimillonario, llamativo para los grupos narcotraficantes. ${ }^{43}$

Si bien los cárteles de la droga no llevan a cabo el tráfico ilícito de migrantes, sí exigen una cuota a los traficantes de migrantes por dejarlos pasar a través de los territorios que los primeros controlan. ${ }^{44} \mathrm{~A}$ mayor abundamiento, el traslado ilícito de migrantes se ha convertido en una forma de añadir ganancias, pues los cárteles han conseguido que los migrantes paguen hasta cinco mil dólares por cruzar el desierto. ${ }^{45}$ Según testimonios de migrantes, les cobran de doscientos a quinientos dólares solo por cruzar la línea fronteriza. ${ }^{46}$ En el año 2008, las "cuotas" que se cobraban a los centroamericanos llegaron a variar entre seis mil y siete mil dólares, y solo el cruce de la frontera les costaba de mil quinientos a dos mil quinientos dólares. ${ }^{47}$

A través de testimonios, el trabajo realizado por Izcara revela que el aumento de las cuotas que tienen que pagar los migrantes por cruzar la frontera subió considerablemente en los años 2007, 2008 y 2009, esto es, durante la guerra contra el narcotráfico, marco temporal de esta investigación. ${ }^{48}$ Por lo tanto, los migrantes originan los siguientes tipos de ingresos para los narcotraficantes: a) pago de rescate por los secuestros, b) pago de cuotas por atravesar territorios bajo el control de los delincuentes, y c) por ingresarlos forzadamente a la delincuencia organizada. ${ }^{49}$

${ }^{42}$ De Génova, Nicholas, "La producción legal de la 'ilegalidad' migrante mexicana", Estudios Migratorios Latinoamericanos, vol. 17, núm. 52, pp. 519-554.

${ }^{43}$ Izcara Palacios, Simón Pedro, "Corrupción y contrabando de migrantes en Estados Unidos", Política y Gobierno, vol. 20, núm. 1, pp. 79-106.

${ }^{44}$ Izcara Palacios, Simón Pedro, "Etiología del tráfico de migrantes en México: relevancia de los factores de atracción", Norteamérica, vol. 12, núm. 2, pp. 29-55.

${ }^{45}$ Vogt, Wendy A., "Crossing Mexico: Structural violence and the commodification of undocumented Central American migrants", American Ethnologist, vol. 40, núm. 4, p. 772.

${ }^{46}$ Gómez Durán, Thelma, "Vivir de los migrantes", Pie de Página, 9 de agosto, 2014. Disponible en: https://enelcamino. piedepagina.mx/historia/vivir-de-el-los-migrantes/

${ }^{47}$ Vogt, Wendy A., "Crossing Mexico: Structural violence and the commodification of undocumented Central American migrants", American Ethnologist, vol. 40, núm. 4, p. 772.

${ }^{48}$ IzCara Palacios, Simón Pedro, "El declive del contrabando de indocumentados en México", Estudios Mexicanos, vol. 28, núm. 2, pp. 351-376.

${ }^{49}$ IzCARA Palacios, Simón, "Violencia postestructural: migrantes centroamericanos y cárteles de la droga en México", Revista de Estudios Sociales, núm. 56, pp. 12-25. 


\section{Desaparición y secuestro de migrantes}

Para ilustrar el fenómeno de la desaparición de migrantes durante los años analizados, tomamos los datos proporcionados por la Comisión Nacional de Derechos Humanos. Esta informó que, entre septiembre de 2008 y febrero de 2009, se llevaron a cabo 9758 secuestros de migrantes, datos congruentes con los de la introducción de este trabajo. Entre enero y diciembre de 2010, la CNDH reportó 11333 víctimas de este crimen. Conforme a los informes especiales sobre secuestro de la Comisión Nacional de Derechos Humanos, $2009^{50}$ y $2011,{ }^{51}$ la cantidad de víctimas secuestradas había aumentado tanto en número como en nivel de violencia. Incluso, muchos migrantes han sido secuestrados y desparecidos sin que ello conste en registros oficiales.

Aunque hay diversos sistemas de registro, tanto a nivel federal como estatal, en el informe especial sobre los casos de secuestro de migrantes, la CNDH expresó además que los secuestros a estos extranjeros ascienden a más de veinte mil por año. Por su parte, el Informe sobre la Situación de las personas migrantes no localizadas y restos no identificados en México presenta un cálculo aproximado de setenta mil desapariciones de migrantes, en el periodo del 2007 al 2012.

Esta grave situación no ha sido de todos conocida, y fue hasta agosto del año 2010 que este flagelo trascendió en la opinión pública, cuando se encontraron en San Fernando Tamaulipas 72 cuerpos de hombres, mujeres y niños que correspondian a migrantes. De los 72 cuerpos, hasta octubre de 2010, se habían reconocido cincuenta personas: cuatro brasileños, un ecuatoriano, diez guatemaltecos, catorce salvadoreños y veintiún hondureños. ${ }^{52}$ Se les encontró atados de las manos, presumiblemente porque se negaron a trabajar para los zetas. Cabe decir que estos últimos, por la intensidad de violencia que ejercían contra la población y la fuerza pública, constituyeron uno de los principales grupos objetivos del presidente Calderón. ${ }^{53}$

\footnotetext{
${ }^{50}$ Comisión Nacional de los Derechos Humanos, "Informe Especial sobre los Casos de Secuestro en Contra de Migrantes", CNDH México, 15 de junio, 2009. Disponible en: https://www.cndh.org.mx/documento/informe-especial-sobre-loscasos-de-secuestro-en-contra-de-migrantes

${ }^{51}$ Comisión Nacional de los Derechos Humanos, "Informe Especial sobre los Casos de Secuestro en Contra de Migrantes", CNDH México, 22 de febrero de 2011.

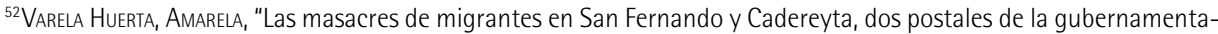
lidad necropolítica de las migraciones en Mesoamérica", Íconos Revista de Ciencias Sociales, núm. 58, pp. 131-147.

${ }^{53}$ Vogt, Wendy A., "Crossing Mexico: Structural violence and the commodification of undocumented Central American migrants", American Ethnologist, vol. 40, núm. 4, p. 773.
} 
Posteriormente, el 7 de abril del 2011, se encontraron 193 restos humanos en 47 fosas clandestinas, en el mismo municipio de Tamaulipas, conforme a la Comisión Interamericana de Derechos Humanos (сіDH). Un año más tarde, en 2012, 49 cuerpos de migrantes fueron encontrados en Cadereyta, Nuevo León. ${ }^{54}$ La privación de la vida de estas personas ocurrió de manera extremadamente violenta; sus cuerpos incluso presentaban huellas de torturas.

Los extranjeros indocumentados en tránsito por el país forman parte de las decenas de miles de desaparecidos en México, aunque por el mismo anonimato de su trayecto y la falta de mecanismos efectivos para llevar un registro confiable, las estadísticas que se presentan en los diversos informes no son equivalentes. ${ }^{55}$ Los datos que proporciona la Secretaría de Gobernación señalan que durante la administración de Felipe Calderón (del 2006 al 2012), se registraron más de veintiséis mil casos de desaparición. ${ }^{56}$ Sin embargo, son la tercera parte de los números que reportan otros organismos como las casas de migrantes, Fundar o wolA. En los dos primeros años de la administración peñista, las estadísticas marcaban que trece personas desaparecían a diario. ${ }^{57}$

La siguiente tabla muestra únicamente los datos que sí fueron registrados en oficinas de El Salvador. En ella se evidencia que, a partir del año 2006, las desapariciones de migrantes salvadoreños incrementaron en forma sustancial.

Registro de migrantes salvadoreños no localizados por año.

\begin{tabular}{|c|c|c|c|c|c|c|c|c|c|c|c|}
\hline 1990 & 1992 & 1994 & 1997 & 1999 & 2001 & 2003 & 2005 & 2006 & 2010 & 2011 & 2012 \\
\hline 3 & 2 & 2 & 5 & 2 & 9 & 3 & 9 & 22 & 37 & 39 & 31 \\
\hline
\end{tabular}

Elaboración propia con datos de Banco de Datos Forenses de Migrantes No Localizados de El Salvador. ${ }^{58}$

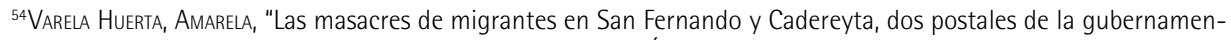
talidad necropolitica de las migraciones en Mesoamérica", Íconos Revista de Ciencias Sociales, núm. 58, p. 6.

${ }^{55}$ Reveles, José, "México: País de desapariciones forzadas", Revista Política y Cultura, Vol. 43, pp. 9- 23.

${ }^{56}$ Martinez, Villarreal Maria Teresa, "Respuestas ciudadanas ante la desaparición de personas en México (20002013)", Espacios públicos, vol. 17, núm. 39, pp. 105-135.

${ }^{57}$ Campa, Homero, "Con Peña Nieto, 13 Desaparecidos al dia", Revista Proceso, núm. 20.

${ }^{58}$ Banco de Datos Forenses de Migrantes No Localzados de El Salvador, "Estadísticas 2010-30 de abril de 2019", Banco de Datos Forenses de Migrantes No Localizados de El Salvador, 2019. Disponible en: https://bancoforenseelsalvador. org/estadisticas/
} 
Si bien no podemos contar con estadísticas confiables sobre la cantidad de secuestros de migrantes, las múltiples acciones emprendidas por los familiares ofendidos dan cuenta del tamaño de este lamentable fenómeno. La gravedad de la situación ha sido tal que en varios estados se crearon Fiscalías Especializadas en Atención a Delitos Cometidos en Contra de Inmigrantes. Específicamente, en las ciudades de Chetumal, Tapachula, Tenosique, Candelaria, Ixepec, Xalapa, Ciudad de México y Saltillo están operando fiscalías especializadas en migrantes. ${ }^{59}$ Lamentablemente, Chiapas, Oaxaca, Tabasco, Sonora y Coahuila únicamente reportaron un total de 5824 delitos contra migrantes en el periodo de 2014 a 2016 y solo existe evidencia de 49 sentencias. $^{60}$

Si bien es cierto que los programas y políticas migratorias han representado detenciones y retornos para los migrantes, la delincuencia organizada también ha frustrado los intentos de los centroamericanos en la ruta migratoria hacia Estados Unidos. De ahí que el éxito de la migración en tránsito por México de los años 2005 al 2016 haya sido de solo 26\% en 2006; 32\% en 2007; 22\% en 2008; 29\% en 2009; 28\% en 2010; 27\% en 2011, y 24\% en 2012. Todo ello, de acuerdo con datos de las siguientes bases: United States Census Bureau, American Community Survey (ACS), Estados Unidos, 2005-2016; US Department Homeland Security (DHS), Yearbook of Immigration Statistics, Estados Unidos, 2005-2016; ;1 y el boletín estadístico de Segob, 2005-2016.

\section{4. ¿Qué determina el método QCA sobre este fenómeno?}

Este estudio utilizó como estrategia empírica un análisis cualitativo comparativo (QCA) para determinar los factores que influyen en la violencia contra migrantes indocumentados en México. De acuerdo con Drozdova, estos métodos de análisis son herramientas útiles, pues organizan la información sistemáticamente, generando valores que resultan útiles para la interpretación cualitativa. Asimismo, permiten eliminar variables que no tienen o que tienen poco impacto en el fenómeno estudiado.

Este abordaje abona a la investigación científica, pues las variables que inciden en un fenómeno son analizadas probabilísticamente de forma rigurosa,

\footnotetext{
${ }^{59}$ Suárez, Ximena; Diaz, Andrés; Knippen, José y Meyer, Maureen, "El acceso a la justicia para personas migrantes en México. Un derecho que existe sólo en el papel", Investigation report, Washington Office for Latin America (woLA), 2017.

${ }^{60}$ SuÁrez, Ximena; Diaz, Andrés; KnipPen, José y Meyer, Maureen, "El acceso a la justicia para personas migrantes en México. Un derecho que existe sólo en el papel", Investigation report, Washington Office for Latin America (woLA), 2017.

${ }^{61}$ Homeland Security, "Yearbook of Immigration Statistics", Department of Homeland Security. Disponible en: https:// www.dhs.gov/immigration-statistics/yearbook
} 
para entender su dependencia potencial con el objeto de estudio. ${ }^{62}$ De esta forma, el método aplica las reglas de la inferencia lógica, cotejando información y evaluando si dichas inferencias están respaldadas por datos. Así es como se obtienen los elementos predictores o de mayor explicación en una cuestión analizada, eliminando las variables no informativas o que no inciden consistentemente.

Si bien otras metodologías señalan un número importante de factores que inciden en un fenómeno, no evalúan cuál de ellos tiene mayor preponderancia o prioridad, tal como lo hace QCA. Por otro lado, un análisis estadístico convencional no permite valorar factores que operan de manera interactiva en un fenómeno. Otra ventaja de utilizar QCA es que produce uno o más resultados a través de una ruta o fórmula, donde se muestran todas las combinaciones de condiciones (variables) posibles de un fenómeno.

Siguiendo a McAlearney, los datos se evalúan a través de dos parámetros que miden el grado y la frecuencia que tendrían las variables en un resultado: consistencia y cobertura (consistency y coverage). ${ }^{63}$ Por ello, brinda una aproximación, alternativa a los métodos tradicionales, para un mejor entendimiento del fenómeno de estudio. QCA ayuda a los investigadores a dar un paso adelante porque identifica los factores y determina las formas en que los mismos se combinan para producir un resultado. Cabe destacar que este método se utiliza cuando no se cuenta con datos estadísticos o estos son ambiguos o inexactos. Tal es el caso de las cifras sobre la criminalidad en contra de migrantes en México, pues, por la falta de denuncias, la continua movilidad del migrante o la falta de actuación de las fiscalías ante estas violaciones, se carece de números confiables.

Este método fue elegido tomando en cuenta que QCA se utiliza para estudiar y explicar fenómenos en donde es complejo desentrañar las causas y es difícil determinar la medida o el intervalo de una variable. Por ello, en este método, los datos con que se nutre el sistema se disponen en forma dicotómica. De este modo, la herramienta permite contrastar la información. ${ }^{64}$

Ahora bien, el método presenta algunas debilidades, por ejemplo, no determina cuál sería el resultado en caso de que cambiara el valor de alguna de

\footnotetext{
${ }^{62}$ Drozdova, Katya y Gaubatz, Kurt TayloR, "Reducing uncertainty: Information analysis for comparative case studies", International Studies Quarterly, vol. 58, núm. 3, 2014, pp. 633-645.

${ }^{63}$ McAlearney, Ann; Walker, Daniel; Moss, Alexandra y Bickell, Nina, "Using Qualitative Comparative Analysis of Key Informant Interviews in Health Services Research: Enhancing a Study of Adjuvant Therapy Use in Breast Cancer Care", Medical Care, vol. 54, núm. 4, pp. 400-405. Disponible en: https://www.ncbi.nlm.nih.gov/pmc/articles/ PMC4792771/

${ }^{64}$ Grofman, Bernard y Schnelder, Carsten, "An introduction to crisp set oca, with a comparison to binary logistic regression", Political Research Quarterly, vol. 62, núm. 4, pp. 662-672.
} 
las condiciones estudiadas. Por otro lado, las rutas o fórmulas de resultados que produce QCA únicamente se relacionan con las variables en cuestión, sin hacer inferencias sobre situaciones o condiciones contrarias. Y esto a pesar de que, para algunos estudios, los investigadores necesitan intercambiar sus variables en busca de hacer deducciones. ${ }^{65}$ Por ello, esta investigación se limita al estudio de las variables enunciadas con anterioridad.

Esta parte del estudio trata de explicar los factores que, durante el periodo de análisis, han tenido mayor incidencia en que algunos estados presenten violencia contra los migrantes centroamericanos y otros no. De ello se deriva la ventaja de utilizar una variable dependiente dicotómica (binaria), además, por la falta de una estadística confiable sobre los casos de crimenes contra migrantes, estos no se podrían representar con un porcentaje. Como se ha expresado, el análisis de QCA permite descartar sistemáticamente las configuraciones causales que no se encuentran presentes en el fenómeno y que no resultan posibles en el análisis cuantitativo. ${ }^{66}$

En el modelo QCA, la tabla de análisis se debe nutrir con variables tanto positivas como negativas para el fenómeno estudiado, esto significa incluir variables que se actualizan y variables que no se actualizan. Cabe destacar que las variables se expresaron como preguntas que solo pueden tener por respuesta "sí" o "no". Tal es el caso de: a) si el estado constituye una ruta migrante; $b$ ) si existió presencia de más de un cártel en el periodo analizado; c) si era un estado violento, y d) si el partido gobernante durante la administración 2006-2012 en el estado estaba alineado con el del presidente en turno.

Las columnas se contestaron con (1) cuando la variable estuvo presente y con (0) cuando no. Sin embargo, para la determinación de esta respuesta fue necesario analizar profundamente los informes y estadísticas señaladas en este manuscrito. La criminalidad contra migrantes es la variable dependiente y las últimas cuatro figuran como variables independientes de las cuales se pretende que QCA determine si pueden o no condicionar este tipo de criminalidad.

Para codificar la variable dependiente: "criminalidad contra migrantes en México" en la tabla comparativa, se tuvieron en cuenta los estados con mayores casos, testimonios y denuncias por criminalidad y secuestros a migrantes a los que se codificó con un 1. La decisión de establecer como unidad de análisis esas entidades federativas se realizó considerando el Informe especial de

\footnotetext{
${ }^{65}$ McAlearney, Ann; Walker, Daniel; Moss, Alexandra y Bickell, Nina, "Using Qualitative Comparative Analysis of Key Informant Interviews in Health Services Research: Enhancing a Study of Adjuvant Therapy Use in Breast Cancer Care", Medical Care, vol. 54, núm. 4, p. 402.

${ }_{66}^{6}$ Santos, Manoel leonardo; Pérez-Liñan, Anibal y Garcia Montero, Mercedes, "El control presidencial de la agenda legislativa en América Latina", Revista de Ciencia Política (Santiago), vol. 34, núm. 3, pp. 511-536.
} 
la Comisión Nacional de los Derechos Humanos sobre los casos de secuestro en contra de migrantes, el reporte The impact of securitization on Central American Migrants ${ }^{67}$ y la información del Instituto Nacional de Migración. Esto debido a que los estados elegidos constituyen una ruta de migrantes o bien, presentaron mayores casos de secuestros y crimenes contra migrantes durante los años 2008, 2009, 2010 y $2011 .^{68}$

Para la selección de los estados también se consideró el estudio realizado por Castillas, ${ }^{69}$ pues este señala las entidades por las cuales los migrantes transitan en su viaje hacia Estados Unidos. Además, explica en dónde se presentan los puntos de origen, bifurcaciones y diferentes trayectorias que siguen los migrantes, y que son consistentes con estudios realizados por otras organizaciones. Asimismo, se incluyó como variable del fenómeno la presencia de dos o más cárteles de la droga en los estados seleccionados, a partir de los estudios que establecen las áreas de influencia de los cárteles mexicanos de Rosen y Zepeda, ${ }^{70}$ y los mapas que muestran los radicales cambios de influencia territorial de los carteles del narcotráfico en México, entre otros.

Ahora bien, para codificar si la entidad es considerada como un estado violento, se partió del número de homicidios por cada 100000 personas por entidad, en el periodo elegido. ${ }^{71}$ Es dable destacar que, dentro de la tabla comparativa, también se incluyeron casos no representativos de violencia en contra de la población migrante durante el periodo analizado. Tal es el caso de Aguascalientes, Baja California Sur, Tlaxcala, San Luis Potosí y Quintana Roo.

\footnotetext{
${ }^{67}$ Véase la figura 2. Map of Overall Crimes Committed Against Migrants, The Impact of Securitization on Central American Migrants p. 20. file://C:/Users/ljjos/Downloads/prp_199_the-impact-of-securitization-on-central-american-migrants.pdf

${ }^{68}$ De acuerdo con el Instituto Nacional de Migración, las entidades con más ilícitos reportados fueron: Tamaulipas (998), Chiapas (705), Oaxaca (569), Tabasco (226), Coahuila (93), Sonora (42), Veracruz (9).

${ }^{69}$ CASTILLAS, Rodolfo, "Las rutas de los centroamericanos por México, un ejercicio de caracterización, actores principales y complejidades", Migración y Desarrollo, núm. 10, p. 167.

${ }^{70}$ Rosen, Jonathan Daniel y Zepeda Martinez, Roberto, "La guerra contra el narcotráfico en México: una guerra perdida", Reflexiones, vol. 94, núm. 1, p. 160.

${ }^{11}$ Se encontró que, entre los estados más violentos durante 2009, 2010, 2011, 2012, se encuentran Guerrero, con 246 homicidios; Tamaulipas, con 116; Sonora, con 88; Michoacán, con 75 y Tabasco, con 35 (cifra obtenida por cada 100000 habitantes de acuerdo al Inegi).
} 
Cuadro 1: Matriz de datos "criminalidad contra migrantes" y condiciones que inciden en este delito

\begin{tabular}{|l|c|c|c|c|c|}
\hline \multicolumn{1}{|c|}{ Estado } & $\begin{array}{c}\text { Crimen } \\
\text { contra } \\
\text { migrantes }\end{array}$ & $\begin{array}{c}\text { a) ruta } \\
\text { migrante }\end{array}$ & $\begin{array}{c}\text { b) presencia } \\
\text { de más de } \\
\text { un cártel }\end{array}$ & $\begin{array}{c}\text { c) estado } \\
\text { violento }\end{array}$ & $\begin{array}{c}\text { d) gobierno } \\
\text { del pan }\end{array}$ \\
\hline Aguascalientes & 0 & 0 & 0 & 1 & 1 \\
\hline Baja California Sur & 0 & 0 & 0 & 0 & 0 \\
\hline Chiapas & 1 & 1 & 1 & 0 & 0 \\
\hline Ciudad de México & 0 & 1 & 0 & 0 & 0 \\
\hline Estado de México & 1 & 1 & 1 & 1 & 0 \\
\hline Guanajuato & 0 & 1 & 1 & 0 & 1 \\
\hline Guerrero & 1 & 1 & 1 & 1 & 0 \\
\hline Michoacán & 1 & 1 & 1 & 1 & 0 \\
\hline Oaxaca & 1 & 0 & 0 & 0 & 0 \\
\hline Quintana Roo & 0 & 0 & 1 & 0 & 0 \\
\hline San Luis Potosí & 1 & 1 & 1 & 0 & 1 \\
\hline Sonora & 1 & 1 & 1 & 1 & 1 \\
\hline Tabasco & 1 & 1 & 0 & 0 & 0 \\
\hline Tamaulipas & 1 & 1 & 1 & 1 & 0 \\
\hline Tlaxcala & 0 & 0 & 0 & 0 & 1 \\
\hline Veracruz & 1 & 1 & 1 & 0 & 0 \\
\hline
\end{tabular}

Elaboración propia.

A manera de ejemplo, en la matriz elaborada, Chiapas es un estado representativo por la criminalidad contra migrantes (1), que constituye ruta migrante (1), en donde existe presencia de cárteles de la droga (1), no es un estado violento (0) y en el tiempo de estudio no tuvo un gobierno panista (0).

A partir de la tabla anterior, el proceso de minimización lógica arrojó las condiciones y variables necesariamente presentes dentro del fenómeno estudiado. La reducción produjo las siguientes fórmulas: 
Cuadro 2: Ruta de combinaciones posibles

\begin{tabular}{|c|c|c|c|}
\hline Condición & Condición & Condición & Cobertura \\
\hline ruta migrante $^{*}$ & presencia de cárteles* & $\sim$ gobierno del PAN & 0.6 \\
\hline ruta migrante* $^{*}$ & presencia de cárteles* & $*$ estado violento & 0.5 \\
\hline
\end{tabular}

En donde * representa la operación de conjunción (y), en tanto representa la operación de negación (ausencia de).

Interpretando el análisis cualitativo comparativo, a partir de los resultados que arroja el programa, tenemos que los casos teóricamente posibles -que se traducen en mayor criminalidad en la población migratoria- son aquellos estados en los que durante el periodo analizado hubo presencia de más de un cártel de la droga. Esto en un contexto de consecuente lucha de territorios y poder entre cárteles, ocasionada por la guerra contra el narcotráfico. Asimismo, encontramos como casos posibles a aquellos estados que forman parte de una ruta migratoria.

El hecho de que el partido gobernante en el estado haya sido el PAN no resultó poder explicar el fenómeno de la violencia contra migrantes. A mayor abundamiento, los resultados reflejaron que la existencia de gobiernos estatales panistas no necesariamente incide en la violencia contra migrantes. Con ello, se confirma la tesis de Guillermo Trejo y Sandra Ley, según la cual, al no existir homologación o alineación partidaria entre la federación y los estados, los índices de violencia dentro de las entidades federativas tienden a incrementar. ${ }^{72}$

La columna cobertura señala el porcentaje de casos que cumplen una configuración considerada verdadera sobre el total de casos que presentan el resultado de interés. En este caso, (0.6) especifica que, de la muestra de 16 estados, en 10 casos se presentó la criminalidad contra migrantes en México. Esto quiere decir que la configuración causal está presente en $60 \%$ de los casos que presentan el resultado de interés. El (0.5) significa que en 50\% de los casos en los que se presenta la configuración (el estado es ruta migrante, existe presencia de cárteles y es un estado violento), se encuentra la criminalidad contra migrantes.

\footnotetext{
${ }^{72}$ Trejo, Guillermo y Ley, Sandra, "Federalismo, drogas y violencia. Por qué el conflicto partidista intergubernamental estimuló la violencia del narcotráfico en México", Política y Gobierno, vol. 23, núm. 1, pp. 11-56.
} 
A través de la metodología QCA, se deduce que, si en el estado hay presencia de más de dos cárteles y la entidad federativa constituye una ruta migratoria, luego entonces, la presencia de estas variables es factor para que se presenten crímenes contra migrantes. Esta es la configuración que se presenta para los estados de Tamaulipas, Chiapas, Estado de México, Michoacán, Veracruz y Guerrero. La otra conexión lógica posible señala que, si en el estado hay presencia de cárteles de la droga, el estado es ruta de migrantes y se diagnostica como un estado con altos índices de violencia, conllevará un porcentaje mayor de crímenes contra migrantes. Tal es el caso de Tamaulipas, Sonora, Michoacán y Guerrero.

Esto implica que la presencia de diversos cárteles de la droga, su consecuente lucha de poder y el combate del gobierno en un estado, así como el hecho de que este constituya un camino para migrantes, son condiciones necesarias en este modelo para la criminalidad contra los extranjeros de paso por nuestro territorio. Estos resultados permiten dar respuesta a la pregunta ¿qué explica la violencia contra migrantes en México? Así, se confirma el planteamiento inicial de este trabajo: la lucha contra una forma de criminalidad, como es el narcotráfico, paradójicamente, generó un aumento de la criminalidad contra la población migrante por territorio mexicano.

\section{Conclusiones}

Los resultados de este artículo sugieren que las transgresiones a los derechos humanos de los migrantes se intensificaron en México a partir de la "guerra contra las drogas" y que la migración indocumentada se ha convertido en una industria para la criminalidad organizada que los extorsiona, secuestra y termina privando de la vida. Si bien se revisó una exhaustiva documentación sobre el caso, también se desarrolló un análisis cualitativo comparativo QCA que permitió analizar de forma sistemática las combinaciones posibles de condiciones causales, es decir, configuraciones de factores que producen el resultado de interés. Otra contribución de este estudio radica en la utilización de la metodología QCA, pues ofrece un abordaje distinto a aquellos con los cuales se ha estudiado el fenómeno objeto de esta investigación. A partir de estos resultados, se pueden ampliar investigaciones futuras.

El desarrollo del análisis cualitativo comparativo QCA arrojó lo siguiente: hay dos variables que, al estar presentes en las dos configuraciones causales verdaderas, son en sí mismas condiciones de necesidad para el resultado de interés. Esto es, para la producción de criminalidad contra migrantes durante el periodo analizado. Ellas son: a) la presencia de los cárteles -en busca de 
control y sobrevivencia ante la narcoguerra- y b) que el estado constituya ruta migrante - rutas que fueron dominadas, a su vez, por el narcotráfico-. Estas han sido las condiciones necesarias para la violencia contra la población migratoria y, para esta investigación, son factores que inciden en la violencia contra migrantes.

Regresando a la otra pregunta que guio la investigación: ¿por qué los cárteles de la droga son predadores de los extranjeros indocumentados? Encontramos que la migración indocumentada constituye una industria para las redes criminales que tratan de subsistir ante la guerra contra el narcotráfico. En su afán de ser más poderosos y sobrevivir ante este enfrentamiento con el gobierno, los cárteles y grupos organizados buscan a la población más vulnerable. Estos delincuentes se han enfocado en los migrantes porque saben que son población indocumentada, que tiene que permanecer anónima; además, pueden ser secuestrados y sus familiares extorsionados para pagar su rescate.

A lo largo de este artículo, se ha argumentado que los migrantes resultan ser víctimas de una lucha contra la delincuencia organizada y que esta ha elevado los niveles de violencia en México. Este estudio encontró que, paradójicamente, la estrategia del gobierno federal en su lucha contra el narcotráfico, en los primeros años del siglo xxI, generó el desarrollo de redes criminales que controlan las rutas migratorias, explotan o extorsionan a migrantes y realizan tráfico de personas en movilidad humana.

\section{Referencias bibliográficas}

Abubakar, Ibrahim; Aldridge, Robert; Devakumar, Delan; Orcutt, Miriam; Burns, Rachel y Barreto, Mauricio, "The UCL-Lancet Commission on Migration and Health: the health of a world on the move", The Lancet, vol. 392, núm. 10164, pp. 2606-2654. Amnesty International, New Reports of Human Rights Violations by the Military, Londres, Amnesty International Publications, 2009.

BADE, Klaus, "Migration History", International Encyclopedia of the Social \& Behavioral Sciences, 2015

BAgley, BRuce, ¿Por qué se está perdiendo la guerra contra la droga? (II): de cucarachas, Estados incapaces y legalizaciones nebulosas, 2011.

Banco de Datos Forenses de Migrantes No Localizados de El Salvador, "Estadísticas 201030 de abril de 2019”, Banco de Datos Forenses de Migrantes No Localizados de El Salvador, 2019. Disponible en: https://bancoforenseelsalvador.org/estadisticas/ Barreda Vidal, Perla Zoraida, "La cooperación bilateral México-Estados Unidos contra la delincuencia organizada trasnacional en el marco de la Iniciativa Mérida”, Revista IUS, vol. 8, núm. 34, pp. 42-60. 
Barros, Guillermo, Refugiados centroamericanos: ¿Protegidos o puestos en riesgo por las tecnologías de la comunicación?, 2017.

Campa, Homero, “Con Peña Nieto, 13 Desaparecidos al día”, Revista Proceso, núm. 20. Castillas, Rodolfo, "Las rutas de los centroamericanos por México, un ejercicio de caracterización, actores principales y complejidades”, Migración y Desarrollo, núm. 10, pp. 157-174.

Comisión Nacional de los Derechos Humanos, "Informe Especial sobre los Casos de Secuestro en Contra de Migrantes", en: https://www.cndh.org.mx/documento/informe-especial-sobre-los-casos-desecuestro-en-contra-de-migrantes

Comisión Nacional de los Derechos Humanos, "Informe Especial sobre los Casos de Secuestro en Contra de Migrantes", сNDH México, 22 de febrero de 2011.

Cuaderno sobre secuestro de migrantes. Dimensión, contexto y testimonios de la experencia de la migración en tránsito por México, México, Centro de Derechos Humanos Miguel Agustín Pro Juárez-Casa del Migrante Saltillo, 2011.

De GÉnova, Nicholas, "La producción legal de la 'ilegalidad' migrante mexicana", Estudios Migratorios Latinoamericanos, vol. 17, núm. 52, pp. 519-554.

Drozdova, Katya y Gaubatz, KuRT TAYlor, "Reducing uncertainty: Information analysis for comparative case studies”, International Studies Quarterly, vol. 58, núm. 3, 2014, pp. 633-645.

Escalante Gonzalbo, Fernando, "Homicidios 2008-2009. La muerte tiene permiso", Nexos, 1 de enero, 2011. Disponible en: https://www.nexos.com.mx/?p=14089

“Extranjeros presentados y devueltos, 2020”, Boletín mensual de estadisticas migratorias. Disponible en: http://portales.segob.gob.mx/es/PoliticaMigratoria/Cuadros BOLETIN?Anual $=2020 \mathrm{CtSecc}=3$

Gómez Durán, Thelma, "Vivir de los migrantes”, Pie de Página, 9 de agosto, 2014.

Disponible en: https://enelcamino.piedepagina.mx/historia/vivir-de-el-losmigrantes/

GonzÁlez, GonzAlo CaRrasco, "La migración centroamericana en su tránsito por México hacia los Estados Unidos”, Alegatos, vol. 27, núm. 83, pp. 169-194.

Grofman, Bernard y Schneider, Carsten, "An introduction to crisp set QCA, with a comparison to binary logistic regression”, Political Research Quarterly, vol. 62, núm. 230 4, pp. 662-672.

Guerrero, Eduardo, "Pandillas y cárteles: La gran alianza”, Nexos, 1 de junio, 2010. Disponible en: https://www.nexos.com.mx/?p=13690

Higareda, Diana y Peralta, Montserrat, "Secuestros azotan a migrantes de Centroamérica”, El Universal, 12 de agosto, 2018. Disponible https://www.eluniversal.com. $\mathrm{mx} /$ nacion/sociedad/secuestros-azotan-migrantes-de-centroamerica

Homeland Security, "Yearbook of Immigration Statistics", Department of Homeland Security. Disponible en: https://www.dhs.gov/immigration-statistics/yearbook 
Izcara Palacios, Simón Pedro, "Corrupción y contrabando de migrantes en Estados Unidos”, Política y Gobierno, vol. 20, núm. 1, pp. 79-106.

Izcara Palacios, Simón Pedro, "El declive del contrabando de indocumentados en México”, Estudios Mexicanos, vol. 28, núm. 2, pp. 351-376.

Izcara Palacios, Simón Pedro, "Etiología del tráfico de migrantes en México: relevancia de los factores de atracción”, Norteamérica, vol. 12, núm. 2, pp. 29-55.

Izcara Palacios, Simón Pedro, "La contracción de las redes de contrabando de migrantes en México", Revista de Estudios Sociales, núm. 48, pp. 84-99.

IzcARA PALACIOS, Simón, "Violencia postestructural: migrantes centroamericanos y cárteles de la droga en México”, Revista de Estudios Sociales, núm. 56, pp. 12-25.

Laczko, Frank y Aghazarm, Christine, Migration, Environment and Climate Change: assessing the evidence, Suiza, International Organization for Migration, 2009.

Martínez, Villarreal María Teresa, "Respuestas ciudadanas ante la desaparición de personas en México (2000-2013)”, Espacios públicos, vol. 17, núm. 39, pp. 105-135.

McAlearney, Ann; Walker, Daniel; Moss, Alexandra y Bickell, Nina, "Using Qualitative Comparative Analysis of Key Informant Interviews in Health Services Research: Enhancing a Study of Adjuvant Therapy Use in Breast Cancer Care”, Medical Care, vol. 54, núm. 4, pp. 400-405. Disponible en: https://www.ncbi.nlm.nih.gov/ pmc/articles/PMC4792771/

Meyer, Maureen, En la encrucijada. Tráfico de drogas, violencia y el Estado mexicano, Washington,

Washington Office on Latin America-The Beckley Foundation Drug Policy Programme, 2007.

Morales Hernández, SAndra, "Central American migrants in transit through Mexico women and gender violence; challenges for the Mexican state”, Procedia-Social and Behavioral Sciences, vol. 161, p. 263-268.

Pereyra, Guillermo, "México: violencia criminal y guerra contra el narcotráfico", Revista Mexicana de Sociología, vol. 74, núm. 3, pp. 429-460.

PrÉvide, SAntiago, "Los roles de las fuerzas armadas en seguridad interior: un estudio comparado en la América Latina del Siglo xxi (2006-2016)”, 2017.

Ravelo, Ricardo, "El reparto del mercado”, Revista Proceso, núm. 28.

Rodríguez Chávez, Ernesto; Berumen, Salvador y Ramos, Luis Felipe, “Migración centroamericana de tránsito irregular por México. Estimaciones y características generales”, Apuntes sobre Migración, México, Centro de Estudios Migratorios del Instituto Nacional de Migración, 2011.

Rosen, Jonathan Daniel y Zepeda Martínez, Roberto, "La guerra contra el narcotráfico en México: una guerra perdida”, Reflexiones, vol. 94, núm. 1.

Sánchez Espinoza, Francisco y JuÁrez Jaime, Claudia, "Política de seguridad en México: combate al narcotráfico. Entre la seguridad nacional y la seguridad pública”, Revista IUS, vol. 13, núm. 44, pp. 229-250. 
Santos, Manoel leonardo; Pérez-Liñán, Aníbal y García Montero, Mercedes, "El control presidencial de la agenda legislativa en América Latina”, Revista de Ciencia Política (Santiago), vol. 34, núm. 3, pp. 511-536.

Secretaría de Gobernación, "Acuerdo Nacional por la Seguridad, la Justicia y la Legalidad", Diario Oficial de la Federación, 25 de agosto, 2008. Disponible en: http://www.dof.gob.mx/nota_detalle.php?codigo=5057719ttfecha=25/08/2008

Seelke, Clare Ribando y Finklea, Kristin, US-Mexican security cooperation: The Mérida initiative and beyond, Washington, Congressional Research Service, 2011.

Slack, JeRemy y Whiteford, ScotT, "Viajes violentos: la transformación de la migración clandestina hacia Sonora y Arizona”, Norteamérica, vol. 5, núm. 2, pp. 79-107.

Solís Delgadillo, Juan Mario; Cerna Villagra, Sarah Patricia y Peris Castiglioni, Carlos Aníbal, “¿Qué explica la violencia legal en Paraguay? Un estudio con intención comparativa”, Perfiles latinoamericanos, vol. 27, núm. 53.

SuÁrez, Ximena; DíAz, Andrés; Knippen, José y Meyer, Maureen, "El acceso a la justicia para personas migrantes en México. Un derecho que existe sólo en el papel”, Investigation report, Washington Office for Latin America (WOLA), 2017.

Trejo, Guillermo y Ley, Sandra, "Federalismo, drogas y violencia. Por qué el conflicto partidista intergubernamental estimuló la violencia del narcotráfico en México", Politica y Gobierno, vol. 23, núm. 1, pp. 11-56.

Varela Huerta, Amarela, "Las masacres de migrantes en San Fernando y Cadereyta, dos postales de la gubernamentalidad necropolítica de las migraciones en Mesoamérica”, Íconos Revista de Ciencias Sociales, núm. 58, pp. 131-147.

Vogt, Wendy A., "Crossing Mexico: Structural violence and the commodification of undocumented Central American migrants", American Ethnologist, vol. 40, núm. 4, pp. 764-780. 